Research

Open Access

\title{
Effect of a heated humidifier during continuous positive airway pressure delivered by a helmet
}

\author{
Davide Chiumello ${ }^{1}$, Monica Chierichetti ${ }^{2}$, Federica Tallarini², Paola Cozzi ${ }^{2}$, Massimo Cressoni², \\ Federico Polli2 ${ }^{2}$ Riccardo Colombo ${ }^{3}$, Antonio Castelli ${ }^{3}$ and Luciano Gattinoni ${ }^{1}, 2$
}

\author{
1 Unità Operativa di Anestesia e Rianimazione, Fondazione IRCCS - 'Ospedale Maggiore Policlinico, Mangiagalli, Regina Elena', via F. Sforza 35, \\ 20122 Milan, Italy \\ 2Istituto di Anestesiologia e Rianimazione, Università degli Studi di Milano, via F. Sforza 35, 20122 Milan, Italy \\ 3Unità Operativa di Anestesia e Rianimazione, Ospedale Luigi Sacco, via G.B. Grassi, 20157 Milan, Italy
}

Corresponding author: Davide Chiumello, chiumello@libero.it

Received: 22 Nov 2007 Revisions requested: 15 Jan 2008 Revisions received: 13 Mar 2008 Accepted: 21 Apr 2008 Published: 21 Apr 2008

Critical Care 2008, 12:R55 (doi:10.1186/cc6875)

This article is online at: http://ccforum.com/content/12/2/R55

(c) 2008 Chiumello et al.; licensee BioMed Central Ltd.

This is an open access article distributed under the terms of the Creative Commons Attribution License (http://creativecommons.org/licenses/by/2.0), which permits unrestricted use, distribution, and reproduction in any medium, provided the original work is properly cited.

\begin{abstract}
Introduction The helmet may be an effective interface for the delivery of noninvasive positive pressure ventilation. The high internal gas volume of the helmet can act as a 'mixing chamber', in which the humidity of the patient's expired alveolar gases increases the humidity of the dry medical gases, thus avoiding the need for active humidification. We evaluated the temperature and humidity of respiratory gases inside the helmet, with and without a heated humidifier, during continuous positive airway pressure (CPAP) delivered with a helmet.
\end{abstract}

Methods Nine patients with acute respiratory failure (arterial oxygen tension/fractional inspired oxygen ratio $209 \pm 52$ $\mathrm{mmHg}$ ) and 10 healthy individuals were subjected to CPAP. The CPAP was delivered either through a mechanical ventilator or by continuous low $(40 \mathrm{l} / \mathrm{min})$ or high flow ( $80 \mathrm{l} / \mathrm{min})$. Humidity was measured inside the helmet using a capacitive hygrometer. The level of patient comfort was evaluated using a continuous scale.

\section{Introduction}

During normal spontaneous breathing, ambient air - apart from being filtered for particles and micro-organisms by the nose and upper airways - is heated to body temperature and humidified, so that it is saturated by the time it reaches the alveoli [1]. Consequently, when the upper airways are bypassed (as in a patient with an endotracheal tube) medical gases, which are drier than ambient air [2], must be heated and humidified by heated humidifiers or heat-moisture exchangers [1] in order to avoid bronchial inflammation, cell damage, impairment of mucociliary clearance and loss of pulmonary function [3-6].
Results In patients with acute respiratory failure, the heated humidifier significantly increased the absolute humidity from $18.4 \pm 5.5 \mathrm{mgH}_{2} \mathrm{O} / \mathrm{l}$ to $34.1 \pm 2.8 \mathrm{mgH}_{2} \mathrm{O} / \mathrm{l}$ during ventilator $\mathrm{CPAP}$, from $11.4 \pm 4.8 \mathrm{mgH}_{2} \mathrm{O} / \mathrm{l}$ to $33.9 \pm 1.9 \mathrm{mgH}_{2} \mathrm{O} / \mathrm{l}$ during continuous low-flow CPAP, and from $6.4 \pm 1.8 \mathrm{mgH}_{2} \mathrm{O} / \mathrm{l}$ to 24.2 $\pm 5.4 \mathrm{mgH}_{2} \mathrm{O} / \mathrm{l}$ during continuous high-flow CPAP. Without the heated humidifier, the absolute humidity was significantly higher with ventilator CPAP than with continuous low-flow and highflow CPAP. The level of comfort was similar for all the three modes of ventilation and with or without the heated humidifier. The findings in healthy individuals were similar to those in the patients with acute respiratory failure.

Conclusion The fresh gas flowing through the helmet with continuous flow CPAP systems limited the possibility to increase the humidity. We suggest that a heated humidifier should be employed with continuous flow CPAP systems. 
humidifier reduced nasal congestion [10,12], upper airway dryness, and dry mouth or nose [13]. In addition, the use of a heated humidifier increased patient satisfaction and the number of hours with CPAP application per night, and the patients indicated that they felt more refreshed on awakening [14].

In clinical practice, the use of a heated humidifier during CPAP is regarded to be optional, and it is normally utilized only when the patient exhibits symptoms of nasal or oral dryness or during prolonged utilization [15-19]. A recent review of NPPV [20] concluded that humidification is usually unnecessary during short-term application of CPAP. However, the last international consensus conference on NPPV in intensive care [7] stated that inadequate humidification of medical gases may cause patient distress, especially if the gases are supplied via a pipeline or cylinder.

At the present time there is no information on the optimal level of humidity of inspired gases during the NPPV. The American National Standards Institute suggested, although not directly for NPPV, that $10 \mathrm{mgH}_{2} \mathrm{O} / \mathrm{l}$ of absolute humidity is the lowest acceptable level needed to minimize mucosal damage in the upper airways [21].

In the acute setting, NPPV is usually delivered via a face mask, but this may cause discomfort, skin lesions and gas leaks [7]. To enhance patient comfort and to permit longer periods of NPPV, a new device - the 'helmet' - has been introduced [2224]. Similar to the carbon dioxide rebreathing that occurs with use of the helmet [25], the high internal gas volume could also serve as a 'mixing chamber' between the heated and humidified expired gases and the dry medical gases entering the helmet. This could raise the levels of heat and humidity of the medical gases, thus avoiding the need for a heated humidifier. The final humidity inside the helmet will depend mainly on two factors: the amount of humidity in the patient's expired gases and the flow of fresh medical gases into the helmet. In addition, the humidifying capability of the respiratory tract may also be influenced by the presence of airway or pulmonary disease [26-28].

The aim of this study, conducted in patients with acute respiratory failure and in a group of healthy individuals, was to evaluate the temperature and humidity of respiratory gases within the helmet, with and without a heated humidifier, during CPAP delivered with a continuous high-flow and low-flow system or with a modern mechanical ventilator.

\section{Materials and methods Population}

Two groups of individuals were studied. The first group included nine patients with acute respiratory failure who required CPAP. The patients' characteristics are shown in Table 1. To be eligible for inclusion in the study, the patients were required to be clinically and haemodynamically stable. The second group included 10 healthy nonsmokers (four males, mean age $25.5 \pm 2.8$ years and weight $74.8 \pm 16.1 \mathrm{~kg}$ ) with no airway disease, rhinitis, nasal surgery, or upper airway infections during the preceding month.

Each patient was informed about the procedure and a physician not involved in the study protocol was present to provide patient care. The study was approved by the institutional review board of our hospital and informed consent was obtained in accordance with Italian national regulations.

\section{Interface}

The helmet (Castar, Starmed, Modena, Italy) is a transparent, latex-free, polyvinylchloride hood, which is joined by a metal ring to a soft polyvinylchloride collar. Two underarm straps attached to the ring prevent it from moving upward when the gas pressurizes it.

The helmet has an internal gas volume of $15 \mathrm{I}$, which is reduced to approximately $12 \mathrm{I}$ when the head is inserted into the helmet [24]. A physician excluded the possibility of air leakage by passing a hand around the collar of the helmet.

\section{Protocol}

The individuals were studied in the semirecumbent position. In the patients, the inspired oxygen fraction and the level of CPAP were maintained constant at the levels previously selected by the attending physician, whereas in healthy individuals the inspired oxygen fraction and the level of CPAP were kept constant at $21 \%$ and $5 \mathrm{cmH}_{2} \mathrm{O}$, respectively.

Different modes of ventilation were evaluated. The first mode was ventilator CPAP, delivered by a SERVO $300 \mathrm{C}$ ventilator (Maquet, Solna, Sweden) set to CPAP with the flow trigger regulated at medium sensitivity. The bias flow rate for the flow trigger was set at $2 \mathrm{l} / \mathrm{minute}$. The second mode was continuous low-flow CPAP (40 l/minute; CPAP flow generator; Harold, Milan, Italy) delivered by a valveless system equipped with a latex reservoir bag with a volume of $10 \mathrm{I}$ at atmospheric pressure and $20 \mathrm{I}$ at $20 \mathrm{cmH}_{2} \mathrm{O}$ pressure (Harold) [29]. The third mode was continuous high-flow CPAP ( $80 \mathrm{l} / \mathrm{m}$ minute), delivered by the same valveless system as above [29]. A spring-loaded mechanical positive end-expiratory pressure valve (Medivalv, Vital Signs, Totowa, N.Y., USA) was used.

A Fisher \& Paykel MR 730 heated humidifier (Fisher \& Paykel, Auckland, New Zeland) equipped with a standard plastic disposable circuit was used as a conditioning system. The medical gas was conditioned by flowing it through a plastic chamber (the humidifying chamber) across the surface of warmed sterile water (vaporization surface). The temperature of the inspiratory gas was monitored by a probe at the end of the inspiratory line and at the chamber outlet. Theoretically, with the MR 730 the water reservoir was heated until the 
Table 1

\begin{tabular}{|c|c|c|c|c|c|c|c|c|c|}
\hline Patient & Age (years) & Sex & $\begin{array}{l}\text { Weight } \\
(\mathrm{kg})\end{array}$ & $\begin{array}{c}\text { CPAP } \\
\left(\mathrm{cmH}_{2} \mathrm{O}\right)\end{array}$ & $\underset{(\mathrm{maH})_{2} / \mathrm{FiO}_{2}}{\mathrm{PaO}_{2}}$ & $\underset{(\mathrm{mmHg})}{\mathrm{PaCO}_{2}}$ & $\mathrm{pH}$ & $\begin{array}{c}\mathrm{RR} \\
\text { (breaths/ } \\
\text { minute) }\end{array}$ & $\begin{array}{c}\text { Cause of } \\
\text { ARF }\end{array}$ \\
\hline 1 & 51 & Female & 110 & 7.5 & 290 & 70 & 7.25 & 25 & $\begin{array}{c}\text { Acute } \\
\text { exacerbation } \\
\text { of COPD }\end{array}$ \\
\hline 2 & 78 & Male & 90 & 7.5 & 274 & 63 & 7.28 & 22 & $\begin{array}{c}\text { Acute } \\
\text { exacerbation } \\
\text { of COPD }\end{array}$ \\
\hline 3 & 63 & Male & 80 & 5 & 230 & 65 & 7.27 & 30 & $\begin{array}{c}\text { Acute } \\
\text { exacerbation } \\
\text { of COPD }\end{array}$ \\
\hline 4 & 77 & Female & 70 & 5 & 170 & 29 & 7.44 & 25 & $\mathrm{CHF}$ \\
\hline 5 & 64 & Male & 95 & 5 & 216 & 37 & 7.38 & 25 & Pneumonia \\
\hline 6 & 74 & Female & 75 & 5 & 170 & 38 & 7.45 & 24 & Pneumonia \\
\hline 7 & 47 & Male & 90 & 10 & 155 & 34 & 7.51 & 25 & Pneumonia \\
\hline 8 & 79 & Female & 70 & 10 & 142 & 39 & 7.45 & 20 & $\mathrm{CHF}$ \\
\hline 9 & 72 & Female & 70 & 10 & 225 & 41 & 7.47 & 25 & $\mathrm{CHF}$ \\
\hline lean \pm SD & $67.2 \pm 11.8$ & $\begin{array}{c}4 \text { males } / 5 \\
\text { females }\end{array}$ & $83.3 \pm 13.9$ & $7.2 \pm 2.3$ & $209 \pm 52$ & $46.2 \pm 15.3$ & $7.39 \pm 0.1$ & $24.5 \pm 2.7$ & \\
\hline
\end{tabular}

ARF, acute respiratory failure; CHF, congestive heart failure; COPD, chronic obstructive pulmonary disease; CPAP, continuous positive airway pressure; $\mathrm{FiO}_{2}$, inspired oxygen fraction; $\mathrm{PaO}_{2}$, partial arterial pressure of oxygen; RR, respiratory rate; $\mathrm{SD}$, standard deviation.

inspiratory gas at the end of the inspiratory line reached the preset temperature [30]. The temperature level of the heated humidifier was set at $37^{\circ} \mathrm{C}$.

Each mode of ventilation was evaluated, in random order, with and without the heated humidifier. A total of six conditions were tested.

\section{Measurements}

Room temperature was constant at 20 to $22^{\circ} \mathrm{C}$. To stabilize the system in each condition, individuals were ventilated for at least 20 minutes before any measurements were taken.

A capacitive hygrometer (Hygroclip, Rotronic, Switzerland) was used to measure temperature and relative humidity inside the helmet (range for relative humidity $5 \%$ to $99 \%$ ). The system incorporates a layer of plastic polymer between two electrodes, which - depending on humidity - can absorb molecules of water. Changes in capacity are correlated to the relative humidity. This system has a very low dead time and good accuracy, with an error of $0^{\circ} \mathrm{C}$ and no variations with time. At the end of each measurement the tip of the capacitive hygrometer was dried to avoid any possible measurement error.

The temperature and relative humidity inside the helmet were previously found to be similar in the different positions within the helmet.
All signals were amplified, digitized and recorded at $0.5 \mathrm{~Hz}$ using a data acquisition software (Colligo, Elekton, Milan, Italy). In each condition, on average, three or four readings from the probe were computed. The absolute humidity was computed using the following equation: absolute humidity = relative humidity $\times\left(0.0387 \times \mathrm{T}^{\wedge} 2-0.6066 \times \mathrm{T}+13.776\right)$, where $\mathrm{T}$ is the temperature (in ${ }^{\circ} \mathrm{C}$ ). The respiratory rate and tidal volume were obtained using the ventilator sensor. The absence of any autotriggering phenomena was ensured.

\section{Subjective evaluation}

At the end of each study condition, patient comfort was rated using a continuous scale. Participants were asked to score their response to the question 'How do you feel in the present condition?' by placing a mark on a continuous line (length 10 $\mathrm{cm})$, ranging from 'worst' $(0 \mathrm{~cm})$, 'poor' $(2.5 \mathrm{~cm})$, 'sufficient' (5 $\mathrm{cm})$, 'good' $(7.5 \mathrm{~cm})$, to 'best feeling' $(10 \mathrm{~cm})$ [24]. The participants were carefully instructed on how to use the scale before starting the protocol.

\section{Statistical analysis}

Ten patients were estimated to be necessary to demonstrate a difference of approximately $3 \mathrm{mg} \mathrm{H}_{2} \mathrm{O} / \mathrm{l}$ in absolute humidity at a statistical significance of 0.05 (two tailed) and a power of 0.80 with a two-way analysis of variance design. Results are expressed as mean \pm standard deviation. A $P$ value less than 0.05 was considered significant. We compared the three CPAP systems with and without the heated humidifier using 
Table 2

Temperature and humidity of ambient air and of the medical gas under various conditions

\begin{tabular}{llll}
\hline & Temperature $\left({ }^{\circ} \mathrm{C}\right)$ & Absolute humidity $\left(\mathrm{mgH}_{2} \mathrm{O} / \mathrm{l}\right)$ & Relative humidity $(\%)$ \\
\hline Ambient air & $20-22$ & $9-12$ & $50-60$ \\
Pipeline medical gases & $20-21$ & $3-4$ & $18-25$ \\
Ventilator medical gases & $22-26$ & $3-4$ & $16-19$
\end{tabular}

two-way analysis of variance for repeated measures, followed - when appropriate - by the Holm-Sidak test.

Comparisons within the same CPAP system in patients with acute respiratory failure and in healthy individuals were conducted using a $t$-test. The statistical analysis was performed using Sigma Stat Software (SPSS, Chicago, IL, USA).

\section{Results}

The temperature and humidity of ambient air, pipeline medical gases and medical gases leaving the mechanical ventilator are shown in Table 2.

\section{Patients with acute respiratory failure}

During ventilator CPAP the mean tidal volume and respiratory rate were $0.67 \pm 0.12 \mathrm{I}$ and $18.0 \pm 4.4$ breaths/minute, respectively. Application of the heated humidifier during all CPAP modes tested significantly raised the temperature, and absolute and relative humidity compared with CPAP without the heated humidifier (Table 3). Temperature and absolute and relative humidity were significantly higher with ventilator CPAP with and without the heated humidifier compared with continuous high-flow CPAP and continuous low-flow CPAP (with the exception of temperature for low-flow CPAP; Table 3). Continuous low-flow CPAP exhibited a significantly higher temperature, absolute and relative humidity compared with continuous high-flow CPAP.

There was no difference in the ability to heat and humidify medical gases between the patients with acute respiratory fail- ure and the healthy individuals. Level of comfort was quite good and without difference between the use or non-use of heated humidifier and the CPAP modes (Figure 1a).

\section{Healthy individuals}

During ventilator CPAP, the mean tidal volume and respiratory rate were $1.02 \pm 0.19 \mathrm{I}$ and $12.2 \pm 3.4$ breaths/minute, respectively. The findings in healthy subjects and in patients with acute respiratory failure were similar except for the continuous low-flow and high-flow CPAP, which exhibited similar temperature and humidity (Table 4). Comfort level was similar with and without the heated humidifier and in all three CPAP modes (Figure 1b).

\section{Discussion}

The main findings of this study, which evaluated the conditioning of medical gases during CPAP with helmet, were as follows. First, the use of a heated humidifier during ventilator CPAP, continuous low-flow and high-flow CPAP significantly increased the temperature and humidity of the gasses within the helmet. Second, taking $10 \mathrm{mgH}_{2} \mathrm{O} / \mathrm{l}$ as the absolute minimum humidity required for medical gases during NPPV, this level was achieved without use of the heated humidifier only during ventilator CPAP. Third, patients with acute respiratory failure and healthy individuals exhibited similar abilities to heat and humidify medical gases. Finally, use of the heated humidifier did not affect the level of patients' comfort.

The airway mucosa (nose, sinuses, trachea and bronchi) is highly vascular, rich in mucosal glands and covered by a

Table 3

Temperature and humidity of the medical gas with and without the heated humidifier in patients with acute respiratory failure

\begin{tabular}{llll}
\hline & Temperature $\left({ }^{\circ} \mathrm{C}\right)$ & Absolute humidity $\left(\mathrm{mgH}_{2} \mathrm{O} / \mathrm{l}\right)$ & Relative humidity $(\%)$ \\
\hline $\mathrm{CPAP}_{\mathrm{VENT}}$ with $\mathrm{HH}$ & $32.4 \pm 1.4^{\mathrm{a}, \mathrm{c}}$ & $34.1 \pm 2.8^{\mathrm{a}, \mathrm{b}, \mathrm{c}}$ & $98.1 \pm 1.8^{\mathrm{a}, \mathrm{c}}$ \\
$\mathrm{CPAP}_{\mathrm{VENT}}$ without HH & $29.5 \pm 2.0^{\mathrm{a}}$ & $18.4 \pm 5.5^{\mathrm{a}, \mathrm{b}}$ & $61.4 \pm 14.7^{\mathrm{a}, \mathrm{b}}$ \\
$\mathrm{CPAP}_{\mathrm{LF}}$ with HH & $32.3 \pm 1.0^{\mathrm{a}, \mathrm{c}}$ & $33.9 \pm 1.9^{\mathrm{a}, \mathrm{c}}$ & $98.0 \pm 1.0^{\mathrm{a}, \mathrm{c}}$ \\
$\mathrm{CPAP}_{\mathrm{LF}}$ without $\mathrm{HH}$ & $28.5 \pm 1.7^{\mathrm{a}}$ & $11.4 \pm 4.8^{\mathrm{a}}$ & $40.4 \pm 15.5^{\mathrm{c}}$ \\
$\mathrm{CPAP}_{\mathrm{HF}}$ with HH & $29.4 \pm 1.1^{\mathrm{c}}$ & $24.2 \pm 5.4^{\mathrm{c}}$ & $82.3 \pm 18.3^{\mathrm{c}}$ \\
$\mathrm{CPAP}_{\mathrm{HF}}$ without HH & $27.4 \pm 1.2$ & $6.4 \pm 1.8$ & $24.6 \pm 6.9$ \\
\hline
\end{tabular}

${ }^{a} P<0.05$ versus $C_{P A P}$;F ${ }^{b} P<0.05$ versus $C_{P A P}{ }_{L F} ;{ }^{c} P<0.05$ versus each mode of $C P A P$ without $H H$. CPAP, continuous positive airway pressure; CPAP ${ }_{V E N T}$, ventilator CPAP; $C_{\text {PAP }}$, continuous low-flow CPAP; CPAP ${ }_{H F}$, continuous high-flow CPAP; HH, heated humidifier. 
Figure 1

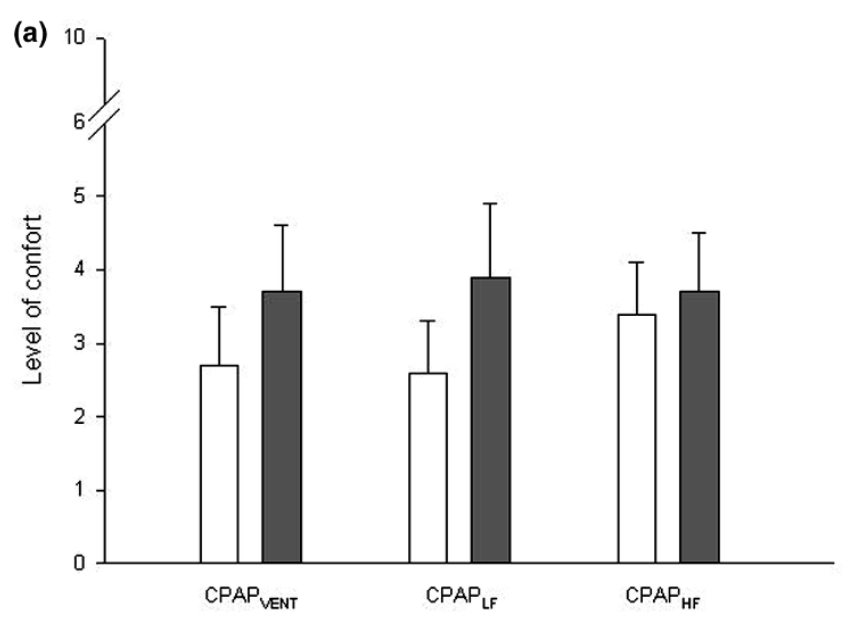

(b)

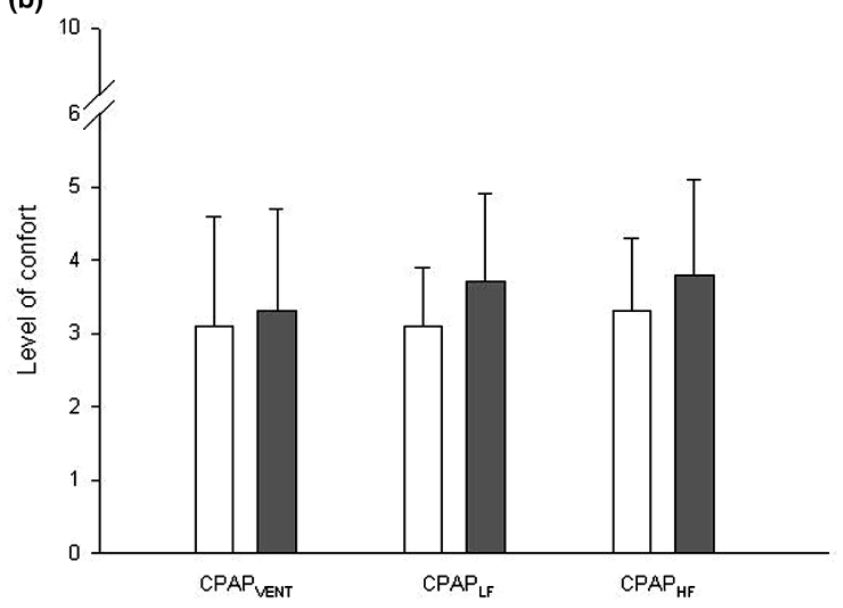

Comfort in patients with acute respiratory failure and healthy individuals with and without heated humidifier. Shown are average ratings of comfort in (a) patients with acute respiratory failure and in (b) healthy individuals with the heated humidifier (white bar) and without the heated humidifier (black bar). CPAP, continuous positive airway pressure; $\mathrm{CPAP}_{\mathrm{HF}}$, continuous high-flow CPAP; $\mathrm{CPAP}_{\mathrm{LF}}$, continuous low-flow CPAP; CPAP $_{\text {VENT }}$, ventilator CPAP.

hygroscopic mucus [1]. During spontaneous breathing, the ambient air, which under normal indoor conditions, has a temperature of $20^{\circ} \mathrm{C}$ to $24^{\circ} \mathrm{C}$ and an absolute humidity between 9 and $12 \mathrm{mgH}_{2} \mathrm{O} / \mathrm{l}$, is progressively heated and humidified through the respiratory system by evaporation of water from the airway mucosa [31]. The air is heated and humidified until it becomes fully saturated by the time it reaches the alveoli (i.e., it reaches an absolute humidity of $44 \mathrm{mgH}_{2} \mathrm{O} / \mathrm{l}$ at a temperature of $37^{\circ} \mathrm{C}$ ). During expiration, the temperature and humidity of the alveolar gas gradually drop, reaching a temperature of $32^{\circ} \mathrm{C}$ to $34^{\circ} \mathrm{C}$ and an absolute humidity of 27 to $34 \mathrm{mgH}_{2} \mathrm{O} / \mathrm{l}$ at the nose $[1,32]$. Thus, at least under normal ambient conditions, the temperature and humidity of the expired gases are always higher than those of ambient air [32,33].
Conversely, in patients with severe obstructive sleep apnoea receiving nasal CPAP delivering ambient air at high flow, the humidity of the inspired gas fell significantly [16]. This high flow of ambient air through the nose increased nasal resistance [12,13], causing discomfort as a result of dryness of the nose and mouth [10]. However, a heated humidifier, by increasing the humidity of the air, relieves or prevents these symptoms $[13,14,16]$.

Medical gases, which are a mixture of oxygen with air, supplied through a pipeline or from a cylinder, are drier than ambient air (Table 2). When these gases are not adequately humidified they can deplete the moisture of the mucosa, reducing ciliary activity and causing functional alterations in the upper airway epithelium [1,3]. It appears reasonable from a physiological point of view that the medical gases should more closely mimic the conditions of normal ambient air [34].

In patients with acute respiratory failure, the face mask is more often used to deliver CPAP rather than a nasal mask because it can deliver higher ventilation pressures [7]. The face mask, with its higher anatomical dead space than that of the nasal mask, can maintain the humidity returned during the expiratory phase, thus increasing the humidity of the inspired gases and counterbalancing the difference between the dry inspired gases and the expired gases at each cycle. Araujo and coworkers [16] found similar levels of humidity using a face mask without a humidifier and a nasal mask with a humidifier. The helmet, which may be a valid alternative interface to the face mask during CPAP [22,24], has a high internal gas volume, similar to a semiclosed environment [25] in which the expired heat and humidity can mix with the fresh gas, thus raising the temperature and humidity of the dry medical gases.

The indications for NPPV depend on the goals of therapy, for instance to reduce the carbon dioxide or to improve oxygenation in patients with acute respiratory failure, and may differ depending upon the clinical context [7]. However, the absence of large-scale controlled studies obtained in different types of populations mean that NPPV cannot unequivocally be indicated in all patients with acute respiratory failure $[7,20]$.

In the present study, we found higher humidity with ventilator CPAP than with the continuous flow CPAP system, and it was also higher than the lowest level required [21,34]. This suggests that the helmet acts as a 'humidity mixing chamber' between expired gases and dry medical gases, making it unnecessary to use a heated humidifier.

Continuous gas flow, as compared with the intermittent flow that occurs during ventilator CPAP, dilutes expired humidity to a greater extent, and therefore it is more difficult to humidify the medical gases adequately. In these conditions a heated humidifier is necessary. Any leakage from the helmet during ventilator CPAP could increase the gas flow delivered by the 
Temperature and humidity of the medical gas with and without the heated humidifier in healthy individuals

\begin{tabular}{llll}
\hline & Temperature $\left({ }^{\circ} \mathrm{C}\right)$ & Absolute humidity $\left(\mathrm{mgH}_{2} \mathrm{O} / \mathrm{l}\right)$ & Relative humidity $(\%)$ \\
\hline $\mathrm{CPAP}_{\mathrm{VENT}}$ with $\mathrm{HH}$ & $31.7 \pm 1.0^{\mathrm{a}, \mathrm{c}}$ & $32.8 \pm 1.7^{\mathrm{a}, \mathrm{c}}$ & $98.1 \pm 1.4^{\mathrm{a}, \mathrm{c}}$ \\
$\mathrm{CPAP}_{\mathrm{VENT}}$ without $\mathrm{HH}$ & $27.6 \pm 1.3^{\mathrm{a}, \mathrm{b}}$ & $12.1 \pm 3.4^{\mathrm{a}, \mathrm{b}}$ & $45.1 \pm 10.9^{\mathrm{a}, \mathrm{b}}$ \\
$\mathrm{CPAP}_{\mathrm{LF}}$ with HH & $31.4 \pm 0.5^{\mathrm{a}, \mathrm{c}}$ & $32.0 \pm 0.8^{\mathrm{a}, \mathrm{c}}$ & $97.2 \pm 1.6^{\mathrm{a}, \mathrm{c}}$ \\
$\mathrm{CPAP}_{\mathrm{LF}}$ without HH & $26.4 \pm 1.3$ & $7.4 \pm 2.2$ & $30.0 \pm 8.4$ \\
$\mathrm{CPAP}_{\mathrm{HF}}$ with HH & $28.5 \pm 0.8^{\mathrm{c}}$ & $24.6 \pm 2.1^{\mathrm{c}}$ & $88.3 \pm 4.8^{\mathrm{c}}$ \\
$\mathrm{CPAP}_{\mathrm{HF}}$ without HH & $25.9 \pm 1.1$ & $7.1 \pm 1.1$ & $29.8 \pm 4.8$
\end{tabular}

aP $<0.05$ versus $\mathrm{CPAP}_{\mathrm{HF}} ;{ }^{\mathrm{b}} P<0.05$ versus $\mathrm{CPAP}_{\mathrm{LF}} ;{ }^{\mathrm{c}} \mathrm{P}<0.05$ versus each mode of $\mathrm{CPAP}$ without $\mathrm{HH}$. CPAP, continuous positive airway pressure; $\mathrm{CPAP}_{\mathrm{VENT}}$, ventilator CPAP; $\mathrm{CPAP}_{\mathrm{LF}}$, continuous low-flow CPAP; $\mathrm{CPAP}_{\mathrm{HF}}$, continuous high-flow CPAP; $\mathrm{HH}$, heated humidifier.

ventilator to maintain the positive end-expiratory pressure level constant, causing an increase in the proportion of the dry fresh gas mixing with the expired gases, thus reducing the ability to achieve adequate humidification.

The heated humidifier significantly increased the temperature and humidity of the medical gases, both by heating and humidifying the medical gases passing through the humidifying chamber, and by achieving a higher level of humidity in the expired gases as they mix with the gases inside the helmet [35]. The heated humidifier with the ventilator CPAP and the continuous low-flow CPAP caused a temperature and absolute humidity similar to those commonly employed during invasive mechanical ventilation [36]. However, with the continuous flow CPAP system, as opposed to the intermittent flow of ventilator CPAP, the heated humidifier did not deliver enough energy to heat the water in the humidification chamber properly, so the medical gases were less conditioned [30].

We studied a rather heterogeneous population of patients with acute respiratory failure, at a range of CPAP from 5 to 10 $\mathrm{CmH}_{2} \mathrm{O}$. The main determinant of the temperature and humidity reached inside the helmet was the inspiratory gas flow passing through the helmet and not the level of CPAP.

In the present study the high temperature and absolute humidity reached using the heated humidifier with ventilator CPAP and continuous low-flow CPAP reduced the transparency of the helmet wall. However, patients rated their comfort similarly, independent of the level of humidity, at least for the short period of investigation reported here.

Previous studies have speculated that airway or pulmonary disease could interfere with the humidifying function of the respiratory tract [26-28]. We did not identify any difference between patients with acute respiratory failure and healthy individuals in terms of the temperature and humidity reached by the medical gases. This suggest (although it was not measured) that the humidity of the expired gases mixed with the fresh gases was similar in patients with acute respiratory failure and healthy individuals. Primiano and colleagues [33] found no difference in the temperature and humidity of the expired gases between patients with cystic fibrosis and healthy individuals breathing ambient air.

\section{Limitations}

Possible limitations of this study must be clarified. First, although the level of humidity during ventilator CPAP was higher than the required minimum, we have no data on longer term use. Global patient comfort, without distinguishing noise, claustrophobia or sensation of heat, was also evaluated only over a short period. Second, only one type of helmet was used, with an internal volume of $15 \mathrm{I}$. However, similar to the case of 'carbon dioxide rebreathing' [25], the volume of the helmet should not directly influence the final level of humidity of the medical gases but only the rate at which the level is reached. We did not also measure leakages from the helmet during the intermittent gas flow delivered by the ventilator. By increasing the gas flow through the helmet, these leakages could result in greater dilution of heat and humidity of expired gases, reducing the temperature and humidity of the inspired gases. Third, because the overall duration of the study was no longer than 2 hours, this prevented us from evaluating other ventilatory modes. However, the data we obtained during ventilator CPAP (intermittent flow) could be also obtained during volume-controlled or pressure-controlled modes.

\section{Conclusion}

During ventilator CPAP without a heated humidifier, the use of a helmet - acting as a mixing chamber between expired and inspired medical gases - increased the humidity of the inspired dry gases to a degree similar to that of ambient air. However, the level of humidity reached with continuous flow CPAP systems, was lower than that of ambient air, and in these cases a heated humidifier is probably indicated.

\section{Competing interests}

The authors declare that they have no competing interests.

\section{Authors' contributions}

DC conceived of the study, participated in its design and coordination, performed the measurements and wrote a first draft 


\section{Key messages}

- The helmet acts as a humidity chamber, rendering the use of a heated humidifier unnecessary during ventilator CPAP.

- Patients with acute respiratory failure and healthy individuals exhibit similar ability to heat and humidify medical gases.

- Use of the heated humidifier during CPAP does not affect patient comfort.

of the manuscript. MC participated in the study design and coordination, performed the measurements and helped to draft the manuscript. FT participated in the study design and coordination, performed the measurements, and helped to draft the manuscript. PC participated in the study design and coordination, and performed the measurements. MC participated in the study design and coordination, and performed the measurements. FP participated in the study design and coordination, and performed the measurements. RC participated in the study design and coordination, and performed the measurements. AC participated in the study design and coordination, and performed the measurements. LG conceived of the study, participated in its design and coordination, coordinated the final analysis of collected data and revised the manuscript, writing its final version.

\section{Acknowledgements}

The authors wish to thank everyone who participated in the study and in the care of the patients enrolled. Special thanks go to the nursing staff of the general intensive care unit of the Fondazione Ospedale Maggiore Policlinico, Mangiagalli, Regina Elena and of Ospedale Luigi Sacco, without whom this study would not have been possible.

\section{References}

1. Shelly MP, Lloyd GM, Park GR: A review of the mechanisms and methods of humidification of inspired gases. Intensive Care Med 1988, 14:1-9.

2. Chiumello D, Gattinoni L, Pelosi P: Conditioning of inspired gases in mechanically ventilated patients. In Yearbook of Intensive Care and Emergency Medicine Edited by: Vincent JL. Berlin: Springer-Verlag; 2002:275-86.

3. Chalon J, Loew DA, Malebranche J: Effects of dry anesthetic gases on tracheobronchial ciliated epithelium. Anesthesiology 1972, 37:338-343

4. Noguchi $\mathrm{H}$, Takumi $\mathrm{Y}$, Aochi O: A study of humidification in tracheostomized dogs. Br J Anaesth 1973, 45:844-848.

5. Rashad K, Wilson K, Hurt HH Jr, Graff TD, Benson DW: Effect of humidification of anesthetic gases on static compliance. Anesth Analg 1967, 46:127-133.

6. Tsuda T, Noguchi H, Takumi Y, Aochi O: Optimum humidification of air administered to a tracheostomy in dogs. Scanning electron microscopy and surfactant studies. Br J Anaesth 1977, 49:965-977.

7. Anonymous: International Consensus Conferences in Intensive Care Medicine: noninvasive positive pressure ventilation in acute Respiratory failure. Am J Respir Crit Care Med 2001, 163:283-291.

8. Mador MJ, Krauza M, Pervez A, Pierce D, Braun M: Effect of heated humidification on compliance and quality of life in patients with sleep apnea using nasal continuous positive airway pressure. Chest 2005, 128:2151-2158.
9. Pepin JL, Leger P, Veale D, Langevin B, Robert D, Levy P: Side effects of nasal continuous positive airway pressure in sleep apnea syndrome. Study of 193 patients in two French sleep centers. Chest 1995, 107:375-381.

10. Togias AG, Naclerio RM, Proud D, Fish JE, Adkinson NF Jr, KageySobotka $A$, et al.: Nasal challenge with cold, dry air results in release of inflammatory mediators. Possible mast cell involvement. J Clin Invest 1985, 76:1375-1381.

11. Togias AG, Naclerio RM, Peters SP, Nimmagadda I, Proud D, Kagey-Sobotka $A$, et al.: Local generation of sulfidopeptide leukotrienes upon nasal provocation with cold, dry air. Am Rev Respir Dis 1986, 133:1133-1137.

12. Hayes MJ, McGregor FB, Roberts DN, Schroter RC, Pride NB: Continuous nasal positive airway pressure with a mouth leak: effect on nasal mucosal blood flux and nasal geometry. Thorax 1995, 50:1179-1182.

13. Richards GN, Cistulli PA, Ungar RG, Berthon-Jones M, Sullivan $\mathrm{CE}$ : Mouth leak with nasal continuous positive airway pressure increases nasal airway resistance. Am J Respir Crit Care Med 1996, 154:182-186.

14. Massie CA, Hart RW, Peralez K, Richards GN: Effects of humidification on nasal symptoms and compliance in sleep apnea patients using continuous positive airway pressure. Chest 1999, 116:403-408.

15. Kallstrom TJ: AARC Clinical Practice Guideline: oxygen therapy for adults in the acute care facility: 2002 revision \& update. Respir Care 2002, 47:717-720.

16. Martins De Araujo MT, Vieira SB, Vasquez EC, Fleury B: Heated humidification or face mask to prevent upper airway dryness during continuous positive airway pressure therapy. Chest 2000, 117:142-147.

17. Rakotonanahary D, Pelletier-Fleury N, Gagnadoux F, Fleury B: Predictive factors for the need for additional humidification during nasal continuous positive airway pressure therapy. Chest 2001, 119:460-465.

18. Schonhofer B, Sortor-Leger S: Equipment needs for noninvasive mechanical ventilation. Eur Respir J 2002, 20:1029-1036.

19. Wood KE, Flaten AL, Backes WJ: Inspissated secretions: a lifethreatening complication of prolonged noninvasive ventilation. Respir Care 2000, 45:491-493.

20. Mehta S, Hill NS: Noninvasive ventilation. Am J Respir Crit Care Med 2001, 163:540-577.

21. American National Standards Institute: Standard for Humidifiers and Nebulizers for Medical Use. ANSI Z79[9] Washington, DC: American National Standards Institute; 1979.

22. Antonelli M, Conti G, Pelosi P, Gregoretti C, Pennisi MA, Costa R, Severgnini $P$, Chiaranda M, Proietti R: New treatment of acute hypoxemic respiratory failure: noninvasive pressure support ventilation delivered by helmet: a pilot controlled trial. Crit Care Med 2002, 30:602-608.

23. Antonelli M, Pennisi MA, Pelosi P, Gregoretti C, Squadrone V, Rocco M, Cecchini L, Chiumello D, Severgnini P, Proietti R, Navalesi $P$, Conti G: Noninvasive positive pressure ventilation using a helmet in patients with acute exacerbation of chronic obstructive pulmonary disease: a feasibility study. Anesthesiology 2004, 100:16-24.

24. Chiumello D, Pelosi $P$, Carlesso E, Severgnini $P$, Aspesi M, Gamberoni C, Antonelli M, Conti G, Chiaranda M, Gattinoni L: Noninvasive positive pressure ventilation delivered by helmet vs. standard face mask. Intensive Care Med 2003, 29:1671-1679.

25. Taccone $P$, Hess $D$, Caironi $P$, Bigatello LM: Continuous positive airway pressure delivered with a 'helmet': effects on carbon dioxide rebreathing. Crit Care Med 2004, 32:2090-2096.

26. Graff TD: Humidification: indications and hazards in respiratory therapy. Anesth Analg 1975, 54:444-448.

27. Green ID, Nasarajah MS: Water vapor pressure of end-tidal air of normals and chronic bronchitics. J Appl Physiol 1968, 24:229-231.

28. Walker JE, Wells RE Jr, Merrill EW: Heat and water exchange in the respiratory tract. $A m J$ Med 1961, 30:259-267.

29. Pelosi P, Chiumello D, Calvi E, Taccone P, Bottino N, Panigada M, Cadringher P, Gattinoni L: Effects of different continuous positive airway pressure devices and periodic hyperinflations on respiratory function. Crit Care Med 2001, 29:1683-1689.

30. Lellouche F, Taillé S, Maggiore SM, Qader S, L'her E, Deye N, Brochard L: Influence of ambient and ventilator output tempera- 
tures on performance of heated-wire humidifiers. Am J Respir Crit Care Med 2004, 170:1073-1079.

31. McFadden ER Jr, Pichurko BM, Bowman HF, Ingenito E, Burns S, Dowling N, Solway J: Thermal mapping of the airways in humans. J Appl Physiol 1985, 58:564-570.

32. Williams R, Rankin N, Smith T, Galler D, Seakins P: Relationship between the humidity and temperature of inspired gas and the function of the airway mucosa. Crit Care Med 1996, 24:1920-1929.

33. Primiano FP Jr, Saidel GM, Montague FW Jr, Kruse KL, Green CG, Horowitz JG: Water vapour and temperature dynamics in the upper airways of normal and CF subjects. Eur Respir J 1988, 1:407-414.

34. Chatburn RL, Primiano FP Jr: A rational basis for Humidity Terapy. Respir Care 1987, 32:249-253.

35. Randerath WJ, Meier J, Genger H, Domanski U, Ruhle KH: Efficiency of cold passover and heated humidification under continuous positive airway pressure. Eur Respir J 2002, 20:183-186.

36. Pelosi $P$, Chiumello D, Severgnini P, De Grandis CE, Landi L, Chierichetti LM, Frigerio A, Munaro M, Park G, Chiaranda M: Performance of heated wire humidifiers: an in vitro study. $J$ Crit Care 2007, 22:258-264 